\title{
Применение обогащенной тромбоцитами плазмы с целью профилактики поздних осложнений и болевого синдрома после герниопластики
}

\author{
А. И. Ткаченко, С. Г. Четвериков, Д. В. Атанасов \\ Одесский национальный медицинский университет
}

\section{Application of the plasm, enriched by thrombocytes for prophylaxis of late complications and the pain syndrome after hernioplasty}

\author{
A. I. Tkachenko, S. G. Chetverikov, D. V. Atanasov \\ Odessa National Medical University
}

\section{Реферат}

Цель. За счет применения обогащенной тромбоцитами плазмы (ОТП) снизить степень выраженности поздних осложнений у больных, оперированных по поводу инцизионных вентральных грыж.

Материалы и методы. В клиническое исследование, проведенное в условиях хирургического отделения Центра реконструктивной и восстановительной медицины (Университетская клиника) Одесского национального медицинского университета с 2013 по 2019 г., включены 84 больных, оперированных по поводу послеоперационных вентральных грыж. Средний возраст больных составил $(60,1 \pm 7,6)$ года, размер грыжевых дефектов - 8,2 см, средний индекс массы тела - 31,8 кг/м². Больным по показаниям выполнен стандартный объем оперативного вмешательства: грыжесечение, герниопластика передней брюшной стенки облегченным (80 г/м²) полипропиленовым имплантатом. Пациентам основной группы после выполнения пластики зону имплантации протеза инфильтрировали активированной аутологичной ОТП, которая была заготовлена путем двойного центрифугирования, в объеме 14 - 38 мл. Пациентам контрольной группы инфильтрацию ОТП не выполняли. Качество жизни пациентов оценивали с помощью стандартизированного опросника SF-36 до операции, а также в послеоперационном периоде. С целью дифференцирования нейропатической боли применяли опросники DN4 и ID Pain.

Результаты. У пациентов обеих групп в послеоперационном периоде отмечали повышение показателей качества жизни. Статистическая достоверность различий показателей была выше у пациентов с надапоневротическим расположением протеза. Показатели физического здоровья и ассоциированные с ними показатели социальной активности, общего состояния здоровья демонстрировали значимо более высокий уровень качества жизни у пациентов основной группы. Показатель общего состояния здоровья у больных после надапоневротической герниопластики с применением ОТП был достоверно выше, чем в контрольной группе - соответственно 69,3 $\pm 3,8$ и 59,7 $\pm 4,1(\mathrm{p}<0,05)$.

Выводы. Техника инфильтрации мягких тканей, контактирующих с полипропиленовым протезом, безопасна, достоверно не увеличивает риск возникновения локальных или системных осложнений. Предложенная методика за счет модификации репаративных процессов в зоне герниопластики способствует интеграции протеза, снижает риск развития и степень выраженности биомеханических нарушений, хронического болевого синдрома, что положительно сказывается на качестве жизни пациентов. Эффективность техники статистически достоверно выше у пациентов после надапоневротической герниопластики.

ключевые слова: обогащенная тромбоцитами плазма; регенераторные цитокины; полипропиленовый сетчатый имплантат; перипротезный фиброз; болевой синдром; биомеханическая дисфункция.

Abstract

Objective. To lower the late complications severity in patients, operated for cicatricial abdominal hernias, due to application of plasm, enriched by thrombocytes (PETH).

Materials and methods. In clinical investigation, conducted in Surgical Department of Centre of Reconstructive and Restoration Medicine (the University Clinic) of the Odessa National Medical University in 2013 - 2019 yrs, were included 84 patients, operated for cicatricial abdominal hernias. Average age of the patients have constituted $(60.1 \pm 7.6)$ yrs, the hernia gate size $-8.2 \mathrm{~cm}$, average value of BMI $-31.8 \mathrm{~kg} / \mathrm{m}^{2}$. The standard volume of operative intervention was done in patients in accordance to indications: hernia incision, hernioplasty of anterior abdominal wall, using a lightweight $\left(80 \mathrm{~g} / \mathrm{m}^{2}\right)$ polypropylene mesh. In the main group of patients after hernioplasty the prosthesis implantation zone was infiltrated with activated autologous PETH, which was prepared, using double centrifugation, in the $14-38 \mathrm{ml}$ volume. In patients of the control group the PETH was not performed. The patients' quality of life was estimated, using the standard questionnaire SF-36 preoperatively, and postoperatively. Questionnaires DN4 and ID Pain were applied with the objective to differentiate the neuropathic pain.

Results. In the patients of both groups the raising of the quality of life indices was noted in postoperative period. Statistical trustworthiness of the indices was higher in patients with the supraaponeurosis localization of the prosthesis. The indices of physical health and associated indices of social activity and general level of health have demonstrated a significantly higher level of the life quality in the patients of the main group. Index of the general health state in patients after the supraaponeurosis hernioplasty, using PETH, was trustworthily higher, then in the control group - accordingly, $69.3 \pm 3.8$ and $59.7 \pm 4.1(\mathrm{p}<0.05)$

Conclusion. The infiltration procedure of the soft tissues, having a contact with polypropylene mesh, is secure, do not trustworthily enhance the risk for occurrence of local and systemic complications. The procedure proposed, due to the reparative processes modification in the hernioplasty zone, promotes the prosthesis integrationa, reduces the risk for development and severity of biomechanical disorders, impacting positively the patients' quality of life. The procedure efficacy is statistically trustworthily higher in patients after the supraaponeurosis hernioplasty.

Keywords: plasm, enriched with thrombocytes; regenerative cytokines; the polypropylene mesh implant; the periprosthesis fibrosis; the pain syndrome; biomechanical dysfunction. 
Послеоперационные вентральные грыжи являются актуальной проблемой современной хирургии из-за их частого возникновения, в том числе у лиц трудоспособного возраста $[1,2]$. Выбор оптимальной тактики лечения крайне важен для профилактики возможных послеоперационных осложнений $[3,4]$, сокращения продолжительности реабилитационного периода и требует многокомпонентного комплексного подхода. Вне обсуждения остается применение сетчатого имплантата как фактора, достоверно снижающего риск развития рецидива грыжи в сравнении с устаревшими аутопластическими методиками [36]. Однако, несмотря на широкий спектр предложенных сетчатых имплантатов, производителям все же не удается достичь их абсолютной биологической совместимости $[5,7]$. К оптимальным из доступных имплантатов можно отнести полипропиленовый ввиду его высокой биологической инертности $[4,8]$. Операционная травма и наличие имплантата в ране инициируют локальный воспалительный процесс. Также вероятно развитие неспецифических воспалительных реакций по типу реакции на инородное тело, препятствующих оптимальной интеграции имплантата в тканях, что в свою очередь может привести к развитию послеоперационных осложнений [1 - 3, $7,8]$. В раннем послеоперационном периоде затянувшаяся альтеративная фаза воспаления в тканях, контактирующих с протезом, сопровождается избыточной экссудацией в зоне аллопластики, вследствие чего формируются серомы (лимфоцеле), которые являются наиболее частым осложнением хирургии грыж передней брюшной стенки, диагностируемым у 4 - 60\% пациентов [1, 3, 7]. В свою очередь наличие серомы служит предиктором локальных инфекционных осложнений, таких как нагноение и отторжение имплантата, некроз кожно-жирового лоскута [3, 4], которые могут проявиться и в отсроченном периоде при благоприятно протекающем раннем послеоперационном периоде.

На данный момент нет убедительных данных и единых доказанных подходов, связанных со снижением частоты развития сером за счет модификации хирургической техники либо снижения факторов риска. Периоперационную эхоскопию в зоне аллогерниопластики все авторы считают обязательной. Показания к активному дренированию и его длительность остаются дискутабельными. Нарушение локального кровоснабжения кожно-жирового лоскута может быть обусловлено значительной мобилизацией от апоневроза, сепарацией структур передней брюшной стенки, избыточной массой тела, выбором хирургической техники диссекции тканей, наличием других чужеродных материалов в тканях, курением, сопутствующей соматической патологией [3, 6]. Неоднократно статистически доказана связь частоты развития сером с выбором техники аллопластики. Значительно увеличивается вероятность формирования серомы, если сетка расположена в непосредственной близости с подкожной жировой клетчаткой (техники onlay, inlay, варианты сэндвич-пластики), за счет постоянного контакта и травма- тизации ткани подвижного лоскута имплантатом $[9,10]$.

Серома может быть диагностирована клинически при ультразвуковом исследовании (УЗИ), по данным которого удается оценить наличие, объем, глубину и частично характер жидкостного содержимого. Также под контролем УЗИ оптимально выполнение тонкоигольной аспирационной пункции, что минимизирует риски, а также позволяет убедиться в завершенности процедуры $[7,11]$. Отсутствие контроля за серомой в зоне аллогерниопластики ведет к формированию лимфокисты, значительному повышению риска локальных инфекционных осложнений и отторжения имплантата, что значительно осложняет течение послеоперационного периода в отдаленные сроки [12, 13].

К факторам профилактики сером, доступным хирургу, можно отнести выбор оптимального объема и техники оперативного вмешательства, инертного имплантата и шовного материала, активное дренирование полости над протезом, локальную компрессию за счет ношения абдоминального бандажа, послеоперационный контроль с помощью УЗИ [12 - 15]. С целью оптимизации регенеративных репаративных процессов локально целесообразно применение продуктов ОТП (Platelet Rich Plasma - PRP) как донатора регенераторных цитокинов и матричных белков [16]. Неоднократно доказано, что такой субстрат стимулирует регенеративные процессы, в том числе за счет ускоренного протекания альтеративной фазы локального воспаления, что ожидаемо окажет положительный эффект в виде минимизации объема экссудата, снижения частоты и степени выраженности сером. Также за счет стимуляции неоангиогенеза и дифференцировки клеточных структур формирующегося комплекса протезсоединительная ткань ожидаемы ускорение и оптимизация репаративных процессов на этапе пролиферативной фазы в условиях менышей ишемизации тканей, что приводит к более раннему формированию зрелой по своему коллагеновому составу рубцовой ткани перипротезно. В отдаленные сроки формирующийся рубец характеризуется меньшей толщиной и большей эластичностью. Такой эффект положительно сказывается на качестве жизни пациентов за счет снижения степени выраженности хронического болевого синдрома, связанного с наличием протеза и рубцово измененных слоев передней брюшной стенки, в которые он интегрируется, что может индуцировать локально нейропатический компонент болевого синдрома. Зрелый, более эластичный и тонкий перипротезный рубец в свою очередь минимизирует степень выраженности биомеханических ограничений в подвижности передней брюшной стенки, что особенно важно для пациентов, оперированных по поводу больших грыжевых дефектов с использованием значительных по размеру имплантатов. Биомеханическая дисфункция по типу «панциря черепахи» отрицательно влияет на качество жизни пациента и крайне сложно поддается коррекции.

Цель исследования: за счет применения ОТП снизить степень выраженности поздних осложнений, а также хро- 
нического болевого синдрома у больных, оперированных по поводу послеоперационных вентральных грыж.

\section{Материалы и методы исследования}

В исследование включены 84 пациента, оперированных по поводу послеоперационных вентральных грыж в хирургическом отделении Центра реконструктивной и восстановительной медицины (Университетская клиника) Одесского национального медицинского университета с 2013 по 2019 г. Средний возраст пациентов составил $(58 \pm 5,3)$ года. Мужчин было 36 , женщин - 48. Больные были разделены на две группы: основную - 40 пациентов (17 мужчин и 23 женщины), которым выполнен стандартный объем оперативного вмешательства (грыжесечение, аллогерниопластика передней брюшной стенки), дополненный местной инфильтрацией мягких тканей в зоне герниопластики аутологичной ОТП, и контрольную - 44 пациента (19 мужчин и 25 женщин), которым выполнена исключительно аллогерниопластика в стандартном объеме. Средний возраст пациентов основной группы составил $(61,2 \pm 6,7)$ года, контрольной - $(58,7 \pm 7,2)$ года. Пациенты основной группы были информированы о технике забора материала, харвестинга, а также введения ОТП, и от каждого пациента письменно получено информированное согласие. План исследования был согласован как фрагмент диссертационной работы, получено заключение комиссии по биоэтике Одесского национального медицинского университета № 120Д от 30.10.2017 г.

Все больные были госпитализированы и оперированы в плановом порядке, на дооперационном этапе обследованы в обязательном объеме: лабораторные исследования, рентгенография органов грудной полости, ЭКГ, по показаниям эхокардиоскопия, спирометрия, консультация смежных специалистов. У 38 пациентов с неоднозначной клинической картиной выполнены визуализирующие исследования (магнитно-резонансная, компьютерная томография) структур передней брюшной стенки, органов брюшной полости с целью оценки состояния опорных и мышечных слоев, выбора варианта пластики, исключения другой значимой патологии брюшной полости. В каждом наблюдении на дооперационном этапе был сформулирован диагноз, который в 15\% наблюдений был изменен интраоперационно ввиду наличия субклинических грыжевых дефектов. Для характеристики грыжевого дефекта использовали SWR классификацию Европейской ассоциации герниологов (табл. 1).

Значимым фактором риска является наличие избыточной массы тела [16]. В нашей выборке 31 (78\%) пациент основной и 33 (74\%) пациента контрольной группы страдали ожирением. Средний индекс массы тела (ИМТ) пациентов основной группы составил $(31,2 \pm 6,4)$ кг $/ \mathrm{M}^{2}$, контрольной - $(32,5 \pm 7,2)$ кг $/ \mathrm{M}^{2}$. В процессе дообследования у 18 (45\%) больных основной группы и у 16 (36\%) больных контрольной группы выявлена сопутствующая суб- и декомпенсированная патология. Сахарный диабет 2-го типа в стадии суб- и декомпенсации (уровень НbA1с больше 7\%) диагностирован у 9 (22\%) больных основной группы и у 11 (25\%) больных контрольной группы.

Больным с грыжевым дефектом W3 с целью профилактики компартмент-синдрома назначали ношение абдоминального бандажа на протяжении не менее 14 сут.

В исследование не были включены пациенты, ранее оперированные по поводу злокачественных новообразований, ввиду дискутабельности некоторых аспектов применения продуктов ОТП у таких пациентов и больные с наличием септического очага. Другим критерием, по которому больных не включали в исследование с целью снижения разнородности исследуемых групп, было дополнение аллогерниопластики абдоминопластикой. По нашему мнению, такие пациенты в данном аспекте должны рассматриваться изолированной группой. Также в исследование не были включены больные после выполнения лапароскопической аллогерниопластики.

Пациентам основной группы интраоперационно из периферического венозного доступа до индукции анестезии выполняли забор крови в подготовленные шприцы с анти-

\begin{tabular}{|c|c|c|c|c|}
\hline \multirow{3}{*}{ Характеристика грыжевого дефекта } & \multicolumn{4}{|c|}{ Группа пациентов } \\
\hline & \multicolumn{2}{|c|}{$\begin{array}{l}\text { основная } \\
(n=40)\end{array}$} & \multicolumn{2}{|c|}{$\begin{array}{c}\text { контрольная } \\
(n=44)\end{array}$} \\
\hline & абс. & $\%$ & абс. & $\%$ \\
\hline \multicolumn{5}{|l|}{ Локализация } \\
\hline M и ML (срединная и сочетанная) & 36 & 90 & 37 & 84 \\
\hline L (латеральная) & 4 & 10 & 7 & 16 \\
\hline \multicolumn{5}{|l|}{ Ширина } \\
\hline W1 (меньше 5 см) & 13 & 32 & 14 & 32 \\
\hline W2 $(5-10 \mathrm{~cm})$ & 23 & 58 & 27 & 61 \\
\hline W3 (больше 10 см) & 4 & 10 & 3 & 7 \\
\hline \multicolumn{5}{|l|}{ Рецидив } \\
\hline RO & 29 & 73 & 32 & 72 \\
\hline R1 & 7 & 17 & 8 & 18 \\
\hline R2+ & 4 & 10 & 4 & 10 \\
\hline
\end{tabular}


коагулянтом ACD-A, которые в дальнейшем служили контейнерами для центрифугирования. Поочередный отбор слоя плазмы с буферным слоем из всех шприцов с последующим повторным центрифугированием и концентрированием ОТП в нижней трети объема позволил получить до 38 мл субстрата ОТП с соблюдением всех требований к количественным концентрационным показателям (тромбоциты, гематокрит). При соблюдении техники субстрат асептичен и применим интраоперационно. Такая модифицированная техника Double Spin позволяет получить значительный объем субстрата в сравнении с известными аналогами и имеет весомые экономические преимущества [15]. Активацию ОТП проводили 10\% раствором хлорида кальция в соотношении 1:10 за 10 мин до применения.

У всех больных выполняли грыжесечение с сепарацией тканей монополярной коагуляцией, а также с применением биполярного диссектора ЕК-300M1 («Патонмед», Украина) в режиме сварки. Выполняли аллогерниопластику структур передней брюшной стенки с использованием сетчатого облегченного (80 г/м²) полипропиленового имплантата Prolene («Ethicon», США). Во всех наблюдениях выбор способа пластики рассматривали индивидуально интраоперационно, опираясь на размер, локализацию, состояние опорных слоев передней брюшной стенки, выраженность подкожной жировой клетчатки, а также тяжесть состояния больного с учетом анестезиологических рисков. Во всех наблюдениях аллогерниопластику можно считать ненатяжной. У больных с грыжевыми дефектами небольшого размера предпочтение отдавали выполнению пластики по технике sublay. Варианты сепарационной компонентной пластики, а также пластику по Рамиресу выполняли при грыжах большого размера. При обширных дефектах и наличии сопутствующей патологии предпочтение отдавали пластике onlay и вариантам так называемой сэндвич-пластики с вынужденным размещением верхнего слоя сетчатого имплантата в непосредственном контакте с подкожной жировой клетчаткой. Аллогерниопластика по технике sublay, а также по технологии TAR выполнена 24 (60\%) пациентам основной группы и 27 (61\%) пациентам контрольной группы. Аллогерниопластика по технике onlay, а также варианты сэндвич-пластики выполнены 16 (40\%) пациентам основной группы и 17 (39\%) пациентам контрольной группы.

Во всех наблюдениях размер имплантата определяли с учетом наложения на опорные слои брюшной стенки отступя около 2 - 3 см от края грыжевых ворот. Сетку фиксировали по периметру нитью Prolene 0/1-0.

Пациентам основной группы локально вносили жидкий субстрат ОТП путем пункционной инфильтрации мягких тканей, контактирующих с протезом. Более контролируемое введение за счет дозированности и безопасности достигалось применением иглы диаметр 0,3 мм, длиной 13 мм. Таким образом значительно снижался риск травмы подлежащих сосудистых структур и кишечника. В процессе инфильтрации преимущество отдавали жировым структурам ввиду наличия в них мезенхимальных стволовых клеток, служащих мишенью для регенераторных цитокинов, привнесенных ОТП [17]. Такой характер введения позволяет равномерно распределить объем ОТП по значительной площади поверхности контакта с имплантатом и поверхности свободного подкожного жирового лоскута по всей поверхности диссекции. Процедура занимала от 4 до 13 мин. Кожно-подкожный лоскут не фиксировали к подлежащим слоям брюшной стенки, так как данные различных авторов о рисках и эффективности данной техники противоречивы $[3,5]$.

В подавляющем большинстве наблюдений пространство над сетчатым протезом, которое оставалось единым, дренировали силиконовым дренажем диаметром 6 мм с продольным сечением («Каммед», Украина) активно по Редону в емкость объемом 200 - 600 мл с давлением 98 кПа. Дренирование применяли у больных после пластики по технике sublay при грыжевых дефектах W1. Дренаж оставался в ране от 2 до 5 сут, так как доказано, что более длительное дренирование достоверно повышает риск возникновения септических осложнений [3]. Другим критерием удаления дренажа служило снижение объема отделяемого до 30 мл в сутки. После удаления дренажа для локального контроля за серозным отделяемым в зоне пластики регулярно выполняли ультразвуковое мониторирование (Esaote MyLab 20 plus Ultrasound System) линейным датчиком с периодичностью от 4 до 7 сут, по данным которого определяли наличие отделяемого и косвенно оценивали его объем, с одномоментным контролем за тонкоигольной пункционной аспирацией с целью достижения завершенности аспирации, а также обеспечения безопасности процедуры. Критерием пункционной аспирации был выбран объем более 30 мл за период менее 4 сут с момента предыдущей пункции $[3,7]$. При меньшем объеме в подавляющем большинстве наблюдений отмечали регресс жидкостного скопления, требовавший единоразового контрольного УЗИ через 2 нед. Объем жидкостных скоплений определяли в сроки до 3 мес в отдельных наблюдениях, однако наиболее показательными можно считать первые 28 сут.

Послеоперационное лечение всех больных включало селективное соблюдение принципов Fast Track Surgery ранняя активизация и самостоятельная ходьба не позднее 12 ч после вмешательства. Пациентам в течение первых суток назначали энтеральное питание [15]. Всем пациентам было рекомендовано ношение абдоминального бандажа до 6 нед после оперативного вмешательства. Режим антибиотикопрофилактики, антибиотикотерапии, профилактики тромбоэмболических осложнений, характер питания были одинаковыми в обеих группах пациентов. В соответствии с соматическим статусом, характером грыжевого выпячивания, а также вариантом пластики предпочтение отдавали антибиотикопрофилактике у соматически сохранных пациентов с грыжевыми дефектами небольших размеров. У отдельных пациентов вынужденно прибегали к антибиотикотерапии.

Для контроля степени выраженности болевого синдрома в раннем послеоперационном периоде применяли визуальную аналоговую шкалу (ВАШ) через 2, 12 ч и 3, 


\begin{tabular}{|lll|}
\hline Таблица 2. & $\begin{array}{l}\text { Уровень болевого синдрома } \\
\text { (количество инъекций аналгетика) } \\
\text { у пациентов основной и контрольной } \\
\text { групп }\end{array}$ \\
\hline \multicolumn{1}{|c|}{$\begin{array}{l}\text { Среднее количество инъекций } \\
\text { декскетопрофена } 50 \text { мг }\end{array}$} & $\begin{array}{c}\text { основная } \\
\text { (n=40) }\end{array}$ & $\begin{array}{c}\text { контрольная } \\
\text { (n=44) }\end{array}$ \\
\hline За одни сутки & $2,2 \pm 0,6$ & $2,6 \pm 0,4$ \\
\hline $\begin{array}{l}\text { На протяжении } \\
\text { послеоперационного периода } \\
\text { в стационаре суммарно }\end{array}$ & $4,1 \pm 1,1$ & $4,7 \pm 0,9$ \\
\hline
\end{tabular}

7, 14 - 18 сут после операции. Оценивали качество жизни пациентов по стандартизированной анкете SF-36 в сроки от 6 до 12 мес. Данные сравнивали с аналогичными данными дооперационного анкетирования [5]. Дополнительно у пациентов с жалобами на наличие боли в области вмешательства проводили дифференциальную диагностику характера болевого синдрома по шкале DN4 (Douleur Neuropatique 4 questions) и опроснику ID Pain.

Сравнительными критериями течения отдаленного послеоперационного периода были определены: наличие рецидива грыжевого дефекта, отсроченных осложнений (спаечная болезнь, свищи, формирование серозоцеле), а также показатели качества жизни согласно шкале SF-36.

Для статистического анализа использовали стандартные и модифицированные алгоритмы (https://docs.google. com). Для сравнения динамики дебита отделяемого в исследуемых группах был применен непараметрический индекс - коэффициент Вилкоксона (внутри группы) и Манна -Уитни (между группами) на одинаковых временных позициях (на выбор). Статистические параметры сравнения: достоверными различия считали при уровне р меньше 0,05. Непараметрический критерий Мак-Немара (внутри группы) и Пирсона $\chi^{2}$ (между группами) на одинаковых временных позициях (на выбор) учитывали при сравнении показателей качества жизни по опроснику SF-36 (https://www.rand36calculator.com). Статистические параметры сравнения: оценочное значение степени свободы $=1 ;$ при $\mathrm{p}<0,05 \chi^{2}=2,54 ;$ при $\mathrm{p}<0,01 \chi^{2}=7,22$.

\section{Результаты}

Результаты лечения оценивали у пациентов основной группы, которым объем оперативного вмешательства был дополнен локальной инфильтрацией зоны имплантации протеза аутологичной ОТП, и у пациентов контрольной

\begin{tabular}{|ccc|}
\hline Таблица 3. & $\begin{array}{l}\text { Оценка интенсивности болевого } \\
\text { синдрома после операции по ВАш } \\
(\mathbf{p}<0,005)\end{array}$ \\
\hline $\begin{array}{c}\text { Сроки } \\
\text { наблюдения }\end{array}$ & $\begin{array}{c}\text { Степень выраженности болевого синдрома (Me) } \\
\text { осноя группа } \\
(n=40)\end{array}$ & $\begin{array}{c}\text { контрольная группа } \\
(\mathrm{n}=44)\end{array}$ \\
\hline 2 ч & $67 \pm 7,2$ & $71 \pm 7,6$ \\
\hline 12 ч & $41 \pm 5,3$ & $43 \pm 6,6$ \\
\hline 3 сут & $21 \pm 4,8$ & $19 \pm 3,6$ \\
\hline 7 сут & $13 \pm 2,6$ & $15 \pm 2,2$ \\
\hline $14-18$ сут & $9,3 \pm 2,2$ & $9,7 \pm 2,7$ \\
\hline
\end{tabular}

группы, которым был выполнен исключительно стандартный объем оперативного вмешательства. В каждой группе в свою очередь пациентам выполняли аллогерниопластику с контактом сетчатого протеза со структурами подкожной жировой клетчатки и с расположением сетчатого имплантата вне контакта с подкожной жировой клетчаткой. По размеру, локализации грыжевого дефекта (см. табл. 1), среднему ИМТ для исследуемых групп характерный достаточно высокий уровень однородности.

В основной группе на этапе дообследования всем 40 (100\%) больным определяли уровень тромбоцитов в крови. Среднее количество тромбоцитов в плазме крови больных основной группы составило $(307 \pm 56) \times 10^{9}$ в 1 л. С целью контроля соответствия ОТП требованиям также определяли уровень тромбоцитов субстрата у 34 (85\%) больных. Среднее количество тромбоцитов в ОТП составило $(1073 \pm 106) \times 10^{9}$ в 1 л. Усредненное отношение числа тромбоцитов ОТП к исходному уровню тромбоцитов цельной крови в основной группе составило 3,5 : 1.

Для достаточного обезболивания пациентам основной и контрольной групп потребовалось определенное количество инъекций аналгетика декскетопрофена (табл. 2). Другие препараты для обезболивания не применялись.

Болевой синдром оценивали также по ВАШ через 2, 12 ч, 3, 7 и $14-18$ сут после операции (табл.3).

Уровень болевого синдрома в исследуемых группах был идентичным. Безусловно, данный метод измерения интенсивности боли не относится к стандартным, но, по нашему мнению, по его результатам косвенно можно судить об отсутствии значимых изменений уровня болевого синдрома в послеоперационном периоде. Согласно данным оценки болевого синдрома по ВАШ отмечена тенденция к снижению его интенсивности в раннем послеоперационном периоде у пациентов основной группы.

\begin{tabular}{|c|c|c|c|c|c|}
\hline \multirow{3}{*}{ Осложнения } & \multicolumn{4}{|c|}{ Группа пациентов } & \multirow{3}{*}{$p$} \\
\hline & \multicolumn{2}{|c|}{$\begin{array}{l}\text { основная } \\
(n=40)\end{array}$} & \multicolumn{2}{|c|}{$\begin{array}{c}\text { контрольная } \\
(\mathrm{n}=44)\end{array}$} & \\
\hline & абс. & $\%$ & абс. & $\%$ & \\
\hline Гематома в зоне аллогерниопластики & 1 & $2,5 \pm 0,3$ & 2 & $4,5 \pm 0,6$ & 0,014 \\
\hline Инфильтрат в зоне аллогерниопластики & 2 & $5 \pm 0,6$ & 2 & $4,5 \pm 0,6$ & 0,23 \\
\hline Краевой некроз кожи & 2 & $5 \pm 0,6$ & 4 & $9,1 \pm 1,1$ & 0,009 \\
\hline Рецидив грыжи (за период наблюдения от 6 до 36 мес) & 1 & $2,5 \pm 0,3$ & 2 & $4,5 \pm 0,6$ & 0,009 \\
\hline
\end{tabular}




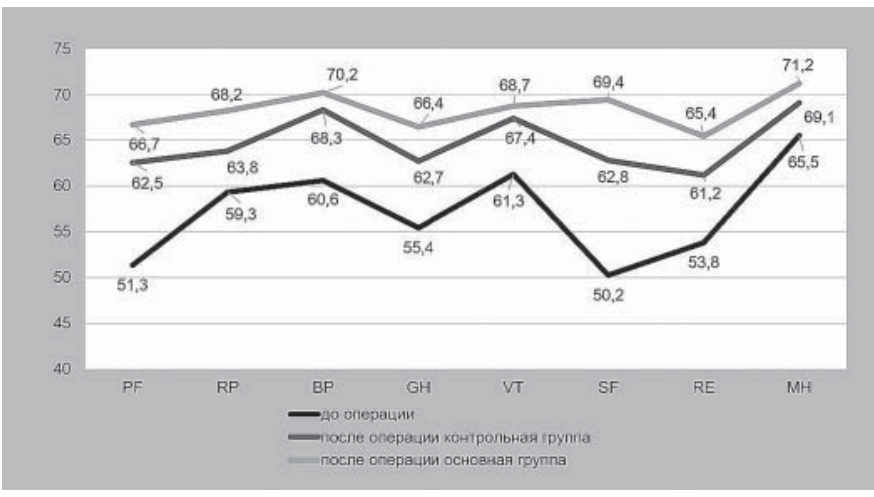

Puc. 1.

Показатели качества жизни пациентов основной и контрольной групп до и после операции. Представлены 8 показателеи:

физическое функиионирование (Physical Functioning - PF); ролевое функционирование, обусловленное физическим состоянием (Role-Physical Functioning - RP); интенсивность боли (Bodily pain - ВP); общее состояние здоровъя (General Health - GH); жизненная активность (Vitality - VT); социальное функционирование (Social Functioning - SF); ролевое функиионирование, обусловленное эмочиональным состоянием (RoleEmotional-RE); nсихическое здоровъе (Mental Health - MH). то же на рис. 2 - 4 .

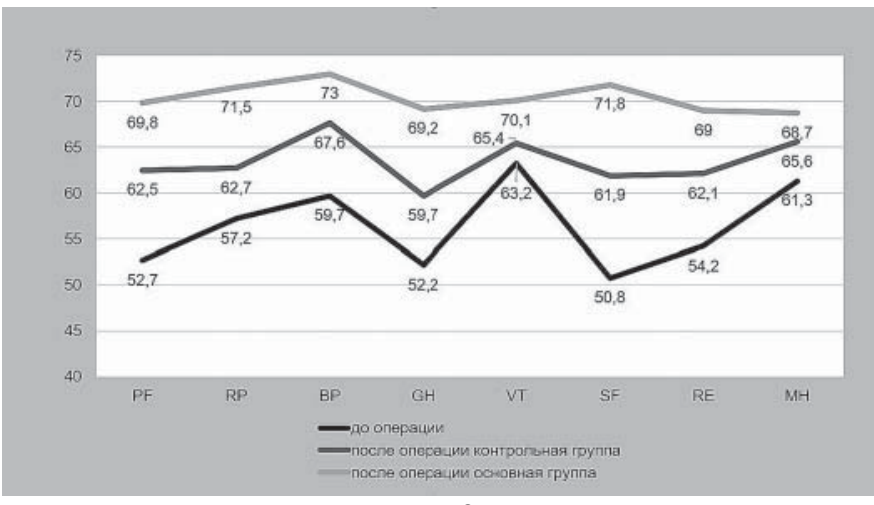

Puc. 2.

Показатели качества жизни пачиентов после аллогерниопластики по технике оnlay и sublay с сэндвич-пластикой.

Проанализированы послеоперационные осложнения у пациентов обеих групп (табл.4). Полученные данные показали отсутствие значимых инфекционных, пирогенных, аллергических послеоперационных осложнений, что может свидетельствовать о достаточной безопасности и полной биологической совместимости ОТП, полученной по предложенной технологии.

Качество жизни оценивали по стандартизированному опроснику SF-36 на дооперационном этапе, а также в послеоперационном периоде в сроки от 6 до 12 мес. Были оперированы повторно по поводу рецидива грыжи 2 пациента. Интенсивный болевой синдром, который был связан с протезированием, так как после дообследования была исключена коморбидная патология, отметили у 5 пациентов (у 2-основной, у 3 - контрольной группы), из которых 4 была выполнена ретромускулярная герниопластика. Средняя интенсивность боли по ВАШ составила $3,5 \pm 0,7$. Согласно шкале DN4 и опроснику ID Pain y

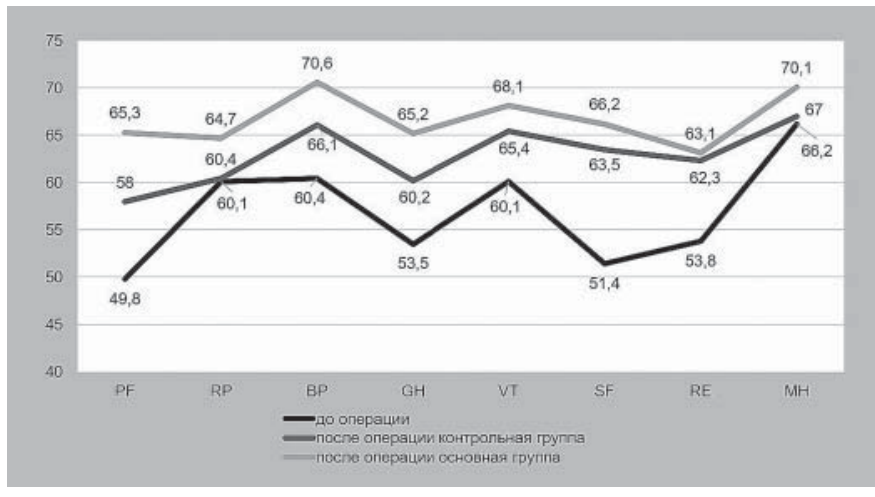

Puc.3.

Показатели качества жизни пациентов после аллогерниопластики по сепаращионным компонентным методикам и технике sublay.

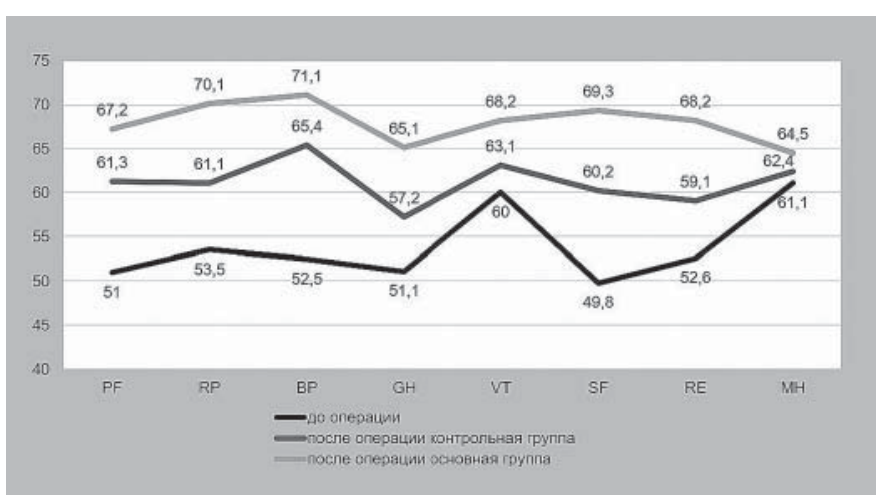

Puc. 4 .

Показатели качества жизни пачиентов с грыжевым дефбектом, превышающим 5 см (W2-3), после аллогерниопластики по технике onlay u sublay с сэндвич-пластикой.

1 пациента основной и 2 пациентов контрольной группы был диагностирован нейропатический характер боли в сроки от 1 до 3 нед. Во всех наблюдениях практически полный регресс болевого синдрома был достигнут применением нестероидных .противовоспалительных препаратов в комбинации с прегабалином (150 - 450 мг в сутки) в сроки от 3 до 10 нед.

Изучена динамика показателей качества жизни с использованием опросника SF-36 у пациентов основной и контрольной групп, а также после аллогерниопластики различного характера (рис. 1 - 4).

У всех пациентов в послеоперационном периоде отмечали повышение показателей качества жизни. Оценка качества жизни у пациентов основной и контрольной групп в зависимости от характера пластики и размера грыжевого дефекта продемонстрировала преимущество предложенной модификации пластики, ряд показателей имел статистически достоверные различия. Статистическая достоверность различий показателей была выше у пациентов с надапоневротическим расположением протеза: аллогерниопластика по технике onlay и sublay с сэндвич-пластикой. 
Показатели ментального состояния пациентов основной и контрольной групп отличались несущественно и не представляли значительного интереса в изучении данной патологии. Также менее значимы были различия показателей результата ролевого функционирования, обусловленного эмоциональным состоянием, однако отмечена тенденция повышения данного показателя у пациентов основной группы независимо от характера пластики.

Остальные показатели физического здоровья и ассоциированные с ними показатели социальной активности, общего состояния здоровья демонстрировали значимо более высокий уровень качества жизни пациентов основной группы. По степени достоверности и количественно различия показателей выше у пациентов после надапоневротической пластики. Показатель GH у больных основной группы после надапоневротической пластики составил 69,3 \pm 3,8 и был достоверно выше, чем в контрольной группе - 59,7 $\pm 4,1(\mathrm{p}<0,05)$.

\section{Обсуждение}

Оценка послеоперационных осложнений в основной и контрольной группах дает основания утверждать, что предложенная техника инфильтрации зоны имплантации протеза аутологичной ОТП не несет никаких дополнительных рисков, что продемонстрировано соответственно минимальным числом осложнений. С помощью количественной оценки осложнений в основной и контрольной группах были получены идентичные показатели. Интенсивность болевого синдрома, которую оценивали по ВАШ, в раннем послеоперационном периоде в основной и контрольной группах не имела существенных статистических отклонений. Эффективность модифицированной техники в уменышении степени выраженности хронического болевого синдрома, а также биомеханической дисфункции, что является определяющим у данных больных критерием оценки физических аспектов качества жизни, отмечена у всех пациентов основной группы в сравнении с контрольной. Статистическая достоверность, а также количественная разница показателей возрастали при их сравнении у пациентов с большим размером грыжевого дефекта, а соответственно с большей площадью использованного протеза при одинаковой технике пластики. Достоверно больше различия были у пациентов, оперированных по методике onlay, sublay с сэндвич-пластикой. В свою очередь количественная разница в показателях была несколько ниже у пациентов с грыжевыми дефектами более 5 см.

Показатель GH у больных основной группы после надапоневротической пластики составил 69,3 \pm 3,8 и был достоверно выше, чем в контрольной группе - 59,7 $\pm 4,1$ (р $<0,05)$. У пациентов с ретромускулярным размещением имплантата основной и контрольной групп статистические различия в показателях качества жизни менее значимы, что можно объяснить малой выборкой и несколько меньшим эффектом применения ОТП при инфильтрации мышечно-апоневротического слоя в сравнении с жировыми структурами при надапоневротической пластике. При этом преимущественно у больных с ретромускулярным размещением протеза отмечали развитие выраженного нейропатического болевого синдрома, с большей вероятностью связанного с техникой оперативного вмешательства - более широкий объем диссекции хорошо иннервируемых мышечно-апоневротических структур, что может приводить к электротравме нервных волокон, а также собственно размещение протеза в ретромускулярном пространстве, где плотность иннервации значительно выше и наличие трансмускулярных швов повышает вероятность травматизации нервных волокон непосредственно швами либо плотным контактом с протезом.

Применение опросников DN4 и ID Pain было эффективным в верификации нейропатического характера боли, что позволило корректно подобрать вариант терапии. Комбинация нестероидных противовоспалительных препаратов с прегабалином эффективно снимала боль у таких больных.

Таким образом, предложенная методика инфильтрации зоны имплантации протеза аутологичной ОТП является безопасной и эффективной для профилактики биомеханической дисфункции, хронического болевого синдрома, что может являться существенным лимитирующим фактором качества жизни пациентов после герниопластики.

\section{Выводы}

1. Выраженный хронический болевой синдром превалировал у больных после ретромускулярной пластики преимущественно по поводу грыж больших размеров.

2. Техника инфильтрации мягких тканей, контактирующих с полипропиленовым протезом, является безопасной, достоверно не увеличивает риск возникновения локальных или системных осложнений.

3. Предложенная методика за счет модификации репаративных процессов в зоне герниопластики способствует интеграции протеза, снижает риск развития и степень выраженности биомеханических нарушений, хронического болевого синдрома, что положительно сказывается на качестве жизни пациентов.

4. Эффективность техники статистически достоверно выше у пациентов после надапоневротической герниопластики.

\section{Подтверждение}

Финансирование. Исследование является фрагментом плановой НИР. Финансирование за счет средств госбюджета.

Конфликт интересов. Авторы, принявшие участие в этом исследовании, декларируют отсутствие у них конфликта интересов.

Вклад авторов. Вклад каждого автора в эту работу одинаков.

Согласие на публикацию. Все авторы прочитали и одобрили окончательный вариант рукописи, а также дали согласие на его публикацию. 


\section{References}

1. Le Huu Nho R, Mege D, Ouaissi M, Sielezneff I, Sastre B. Incidence and prevention of ventral incisional hernia. J Visc Surg. 2012;149 (5 Suppl):e3-14. doi: 10.1016/j.jviscsurg.2012.05.004.

2. Dietz UA, Winkler MS, Härtel RW, Fleischhacker A, Wiegering A, Isbert $\mathrm{C}$, et al. Importance of recurrence rating, morphology, hernial gap size, and risk factors in ventral and incisional hernia classification. Hernia. 2014;18(1):19-30. doi: 10.1007/s10029-012-0999-x.

3. Zhuchenko OP, Zhuchenko AO. Profilaktyka infiltratyvno-zapalnykh uskladnen pisliaoperatsiinykh ran u khvorykh na neuskladneni formy hryzh perednoi cherevnoi stinky. Visnyk Vinnytskoho natsionalnoho medychnoho universytetu. 2014;18(1):133-6. [In Ukrainian].

4. Feleshtynskyi YaP, Smishchuk VV, Vatamaniuk VF. Metodyka roziednannia anatomichnykh komponentiv perednoi cherevnoi stinky u poiednanni z intraperytonealnoiu aloplastykoiu pry hihantskykh pisliaoperatsiinykh hryzhakh zhyvota. In: Zbirnyk naukovykh prats spivrobitnykiv NMAPO im. P. L. Shupyka. 2015;24(1):111-20. [In Ukrainian].

5. Ioffe OYu, Tarasiuk TV, Shvets IM, Stetsenko OP, Tsiura YuP. Otsinka pisliaoperatsiinoho bolovoho syndromu pry riznykh vydakh hernioplastyky pupkovykh hryzh. Khirurhiia Ukrainy. 2014;(3):67-70. [In Ukrainian].

6. Kondratenko BM. Choice of the treatment tactics in patients, suffering postoperative hernia of anterior abdominal wall with concomitant morbid obesity. Klin Khir. 2015;(8):13-6. PMID: 26591855 [In Ukrainian].

7. Amid PK. Classification of biomaterials and their related complications in abdominal wall hernia surgery. Hernia. 1997;1(1),15-21. doi: 10.1007/ bf02426382.

8. Hrubnik VV, Parfentieva ND, Parfentiev RS. Suchasni metody khirurhichnoho likuvannia velykykh ventralnykh hryzh iz vidnovlenniam funktsii miaziv perednoi cherevnoi stinky. Shpytalna khirurhiia. Zhurnal imeni L. Ya. Kovlchuka. 2016;(2):10-2. [In Ukrainian].
9. Brek OO. Morphometric and histological changes of tissues in patients, who underwent operations for postoperative abdominal hernias. Klin Khir. 2015;(5):27-30. PMID: 26419029. [In Ukrainian].

10. Ioffe OYu, Tarasiuk TV, Stetsenko OP, Tsiura YuP, Kryvopustov MS. Zastosuvannia kontseptsii shvydkoho vidnovlennia (fast track) pry likuvanni khvorykh z pisliaoperatsiinymy ventralnymy hryzhamy. Khirurhiia Ukrainy. 2016;(1):41-5. [In Ukrainian].

11. Alishev OT. Novyie podhodyi v profilaktike posleoperatsionnyih oslozhneniy pri proteziruyuschey gernioplastike posleoperatsionnyih ventralnyih gryizh bolshih razmerov. Vestnik sovremennoy klinicheskoy meditsinyi. 2014;7(2):15-21. [In Russian].

12. Plechev VV, Plechev VV, Kornilaev PG, Feoktistov DV, Shavaleev RR, Hakamov TSh. Eksperimentalnaya otsenka effektivnosti sposoba profilaktiki ranevyih oslozhneniy pri implantatsionnoy gernioplastike. Meditsinskiy vestnik Bashkortostana. 2013;8(6):171-3. [In Russian].

13. Brek O. Stan spoluchnoi tkanyny ta yoho vplyv na rezultaty khirurhichnoho likuvannia patsiientiv z pisliaoperatsiinymy ventralnymy hryzhamy. Kharkivska khirurhichna shkola. 2015;(1):31-5. [In Ukrainian].

14. Feleshtynskyi YaP, Smishchuk VV, Lepskyi VV. Intraabdominalna aloplastyka u poiednanni z operatsiieiu Ramirez pry hihantskykh pisliaoperatsiinykh hryzhakh zhyvota. Khirurhiia Ukrainy. 2015;(2):9-13.

15. Dhurat R, Sukesh M. Principles and methods of preparation of plateletrich plasma: A review and author's perspective. J Cutan Aesthet Surg. 2014;7(4):189-97. doi: 10.4103/0974-2077.150734.

16. Fareed WM, Tandon P, Ahmad ZE, Gazal G, Hussain Khan A, Zaidi T, et al. Efficacy of Blood and Its Products-boon for Oral Surgeons: Review. J Univer Surg. 2017;5:1. doi: doi.org/10.21767/2254-6758.100071.

Надійшла 23.06.19 